Research Article

\title{
Sex-Specific Association between Serum 25-Hydroxyvitamin D and Metabolic Risk Factors in T2DM Patients
}

\author{
Xiaomin Sun, ${ }^{1}$ Sirui Zhou, ${ }^{1}$ Xin He, ${ }^{2,3}$ Youfa Wang, ${ }^{1}$ and Wei Cui $\mathbb{D}^{2}$ \\ ${ }^{1}$ Global Health Institute, School of Public Health, Xi'an Jiaotong University Health Science Center, 76 West Yanta Road, Xi'an, \\ Shaanxi 710061, China \\ ${ }^{2}$ Department of Geriatric Endocrinology, First Affiliated Hospital, Xi'an Jiaotong University Health Science Center, \\ 76 West Yanta Road, Xi'an, Shaanxi 710061, China \\ ${ }^{3}$ Department of Endocrinology, Xi'an Aerospace General Hospital, 159 Jitai Road, Yanta District, Xi'an, Shaanxi 710061, China
}

Correspondence should be addressed to Wei Cui; doctorweiwei.cui@126.com

Received 6 August 2019; Revised 10 December 2019; Accepted 18 December 2019; Published 4 June 2020

Academic Editor: Michaela Luconi

Copyright ( 2020 Xiaomin Sun et al. This is an open access article distributed under the Creative Commons Attribution License, which permits unrestricted use, distribution, and reproduction in any medium, provided the original work is properly cited.

Objective. To evaluate the relationship between serum 25-hydroxyvitamin $(25(\mathrm{OH}) \mathrm{D})$ levels and metabolic risk factor levels in patients with type 2 diabetes mellitus (T2DM) on a sex-specific basis. Methods. Our study comprised 507 patients with T2DM (321 men, 186 women; median age, 59 years). The metabolic risk factors examined included lipoprotein(a), glycated albumin (GA-L), and random blood glucose (RBG); the levels of these parameters were determined enzymatically. Serum $25(\mathrm{OH}) \mathrm{D}$ levels were measured by commercial ELISA kits. Participants were divided into low and high $25(\mathrm{OH}) \mathrm{D}$ groups according to the median $25(\mathrm{OH}) \mathrm{D}$ concentration $(13.2 \mathrm{ng} / \mathrm{mL})$. Two-way analysis of covariance and multiple linear regression analysis were performed. Results. The median 25(OH)D concentration was $13.9 \mathrm{ng} / \mathrm{mL}$ in men and $12.2 \mathrm{ng} / \mathrm{mL}$ in women. 25(OH)D levels inversely correlated with levels of three metabolic risk factors in a sex-dependent manner after adjusting for several confounding factors. These were lipoprotein(a) in men $(141.3 \pm 137.9$ and $195.3 \pm 204.8 \mathrm{mg} / \mathrm{L}$ in high and low $25(\mathrm{OH}) \mathrm{D}$ groups, respectively; $P<0.05)$; GA-L in women $(22.2 \pm 8.8 \mathrm{vs}$. $23.3 \pm 7.3 \%$ in high and low $25(\mathrm{OH}) \mathrm{D}$ groups, respectively; $P<0.05)$. In a subgroup analysis, serum $25(\mathrm{OH}) \mathrm{D}$ levels inversely correlated with lipoprotein(a) levels in men $(\beta=-0.185, P=0.002)$ and RBG levels in women $(\beta=-0.176, P=0.028)$. Conclusion. Higher serum $25(\mathrm{OH}) \mathrm{D}$ levels indicate a more favorable lipid profile in men and a more favorable glucose profile in women.

\section{Introduction}

Type 2 diabetes mellitus (T2DM) is a global public health concern that threatens the economies of all nations and developing countries in particular [1]. In a nationally representative survey in mainland China, the estimated overall prevalence of diabetes was $10.9 \%$, with $60 \%$ of diabetic patients unaware of their diagnosis [2]. In addition, more than $50 \%$ of Chinese people with glucose metabolism disorders are vitamin D-deficient [3].

Vitamin D regulates calcium and phosphorus homeostasis, and in the last few decades, its receptors have been observed in several types of insulin-sensitive tissue, such as muscle, fat, and hepatic tissue [4]. Mounting evidence implicates a low level of 25 -hydroxyvitamin D (25(OH)D), the storage form of vitamin $\mathrm{D}$ and the form used in the evaluation of vitamin $\mathrm{D}$ status, has been associated with high incidence of T2DM and metabolic syndrome $[5,6]$.

In the Third National Health and Nutrition Examination Survey, the levels of $25(\mathrm{OH}) \mathrm{D}$ negatively correlated with insulin resistance in non-Hispanic whites and Mexican Americans but not African-Americans [7]. These findings suggest that this relationship is ethnicity-dependent. However, there are limited studies evaluating the relationship between $25(\mathrm{OH}) \mathrm{D}$ concentrations and metabolic risk factors in Chinese populations [8-14], especially in T2DM patients [12-14]. Lu et al. [8] linked this relationship to glucose control in their study of individuals in East China. However, sex-specific differences have not been explored, although several studies indicate that the association 
between $25(\mathrm{OH}) \mathrm{D}$ levels and metabolic risk was stronger in men than women $[9,10]$. The objective of our study was to evaluate the relationship between serum 25(OH)D and metabolic risk factors, and whether the relationships differ by sex in T2DM patients in China.

\section{Materials and Methods}

2.1. Subjects. The study recruited T2DM patients from the First Affiliated Hospital of Xi'an Jiaotong University. Subjects were excluded if they had missing laboratory $(n=40)$ or personal $(n=38)$ data, were younger than 18 years old, $(n=2)$, or were taking calcium or vitamin $\mathrm{D}$ supplements $(n=9)$. Finally, a total of 507 subjects were enrolled. Among these, 251 (49.5\%) had received insulin treatment, 236 (46.5\%) had taken antihypertensive drugs, and 81 (16.0\%) had taken lipidlowering drugs. Analyses involving glycated albumin (GA-L) levels were conducted on 449 subjects only (285 men and 164 women) owing to lack of data for the remaining subjects. The study was approved by the ethics committee at Xi'an Jiaotong University Health Science Center. Written consent was obtained from all participants, and the procedures were implemented in accordance with the approved guidelines.

2.2. Measurements. T2DM was defined as self-reported diabetes previously diagnosed by health-care professionals and was confirmed via a validated supplementary questionnaire that assessed blood test, symptoms, and therapy. Patients whose glycosylated hemoglobin (HbA1c) levels were $\geq 6.5 \%$ in a serological test in this study, but were $<6.5 \%$ previously, were considered to have newly diagnosed T2DM as defined by the American Diabetes Association [11].

The following demographic information was collected from the medical records by the medical staff: age, sex, height, weight, treatment time, marital status, smoking status, alcohol use, insulin use, family history of diabetes, and diabetes duration. Body mass index (BMI) was calculated by dividing the body mass in kilograms by the square of the height in meters $\left(\mathrm{kg} / \mathrm{m}^{2}\right)$. Systolic blood pressure and diastolic blood pressure were measured by accredited nurses.

The metabolic risk factors examined in our study were random blood glucose (RBG), GA-L, HbA1c, lipoprotein(a), total cholesterol (Total-C), low-density lipoprotein cholesterol (LDL-C), high-density lipoprotein cholesterol (HDL-C), triglycerides, and apolipoprotein (Apo) A, ApoB, and ApoE. Blood samples for measurements of all factors except RBG and GA-L were obtained from the patients after they had fasted for at least 8 hours. HbA1c levels were measured via high-performance liquid chromatography (Bio-Rad Variant II; Bio-Rad, Hercules, CA, USA). Levels of the remaining risk factors were determined enzymatically using an automated analyzer (LABOSPECT 008; Hitachi High-Technologies, Tokyo, Japan). ApoA/ApoB and HDL-C/LDL-C ratios were calculated. Serum $25(\mathrm{OH}) \mathrm{D}$ concentrations were determined using an electrochemiluminescence assay (Roche Diagnostics $\mathrm{GmbH}$, Mannheim, Germany). High and low 25(OH)D group were divided according to the median values of $25(\mathrm{OH})$ $\mathrm{D}$ levels $(13.2 \mathrm{ng} / \mathrm{mL})$, respectively. The intra- and interassay coefficients of variability were both $<10 \%$ for $25(\mathrm{OH}) \mathrm{D}$ levels.
2.3. Statistical Analysis. All statistical analyses were performed using SPSS software, version 22.0 (SPSS, Inc., Chicago, IL, USA). The Kolmogorov-Smirnov test was used to assess the normality of data distribution; the values for 25(OH)D, RBG, HbA1c, ApoB, ApoE, lipoprotein(a), Total-C, LDL-C, HDL-C, and triglycerides were logtransformed prior to analysis. Student's $t$-test (for normally distributed variables) and the Mann-Whitney $U$-test (for nonnormally distributed variables) were used to evaluate the significance of differences between the sex. The influence of sex and $25(\mathrm{OH}) \mathrm{D}$ concentration on the levels of the metabolic risk factors was assessed via two-way analysis of covariance (ANCOVA) adjusted for the appropriate covariates. A post hoc test with the Bonferroni correction was used to identify significant differences if a significant main effect or interaction was observed. Normally distributed variables are presented as mean \pm standard deviation, skewed variables as median (interquartile range), and categorical variables as percentages, unless otherwise indicated. The statistical significance level was set at $P<0.05$.

\section{Results}

The median age of the 507 T2DM patients in our study was 59 years, and $321(63.3 \%)$ patients were men. The percentage of patients with vitamin D deficiency $(<20 \mathrm{ng} / \mathrm{mL})$ and vitamin D insufficiency $(20-30 \mathrm{ng} / \mathrm{mL})$ was $78.5 \%$ and $18.9 \%$, respectively (Supplemental Table 1). The median $25(\mathrm{OH}) \mathrm{D}$ level was $13.9 \mathrm{ng} / \mathrm{mL}$ in men and $12.2 \mathrm{ng} / \mathrm{L}$ in women.

Women weighed less than did men and were shorter (both $P$ values $<0.05$ ) (Table 1 ). They also had lower BMIs and diastolic blood pressures and higher ApoA, ApoE, Total$\mathrm{C}$, HDL-C, and phosphorus levels and ApoA/ApoB ratios (all $P$ values $<0.05$ ). There were no other significant difference between men and women.

To identify interactions between $25(\mathrm{OH}) \mathrm{D}$ and sex on metabolic risk factors, two-way ANCOVA was performed after adjusting for age, BMI, season, marital status, smoking status, alcohol use, insulin use, family history of diabetes, and diabetes duration (Table 2 and Figure 1). Significant interactions between $25(\mathrm{OH}) \mathrm{D}$ and sex on lipoprotein(a) and GA-L were observed $(P<0.05)$. High 25(OH)D levels correlated with favorable lipoprotein(a) levels in men $(141.3 \pm 137.9$ and $195.3 \pm 204.8 \mathrm{mg} / \mathrm{L}$ for high and low $25(\mathrm{OH}) \mathrm{D}$ groups, respectively; $P<0.05)$. High $25(\mathrm{OH}) \mathrm{D}$ levels correlated with low GA-L levels in women $(2.2 \pm 8.8 \%$ and $23.3 \pm 7.3 \%$ for high and low $25(\mathrm{OH}) \mathrm{D}$ groups, respectively; $P<0.05)$.

Because the association between $25(\mathrm{OH}) \mathrm{D}$ and metabolic risk factors differed according to sex, we performed separate multiple linear regression analyses in men and women (Table 3). As shown in Model 1, 25(OH)D levels negatively correlated with lipoprotein(a) levels in men $(\beta=-0.203, \quad P<0.001)$ and RBG levels in women $(\beta=-0.150, P=0.041)$. These relationships remained significant after adjusting for several confounding factors including BMI (Models 2 and 3). 
TABLE 1: Subject characteristics in 507 adults with type 2 diabetes according to sex.

\begin{tabular}{|c|c|c|c|c|}
\hline Variable & $\begin{array}{l}\text { Overall } \\
N=507\end{array}$ & $\begin{array}{c}\text { Male } \\
N=321\end{array}$ & $\begin{array}{l}\text { Female } \\
N=186\end{array}$ & $P$ value \\
\hline Age (years) & $59(52-68)$ & $57(50-66)$ & $63(56-70)$ & $<0.001$ \\
\hline Weight (kg) & $68(60-77)$ & $72(65-80)$ & $60(55-68)$ & $<0.001$ \\
\hline Height $(\mathrm{cm})$ & $168(162-174)$ & $172(168-176)$ & $160(156-165)$ & $<0.001$ \\
\hline BMI $\left(\mathrm{kg} / \mathrm{m}^{2}\right)$ & $24.2(22.3-26.2)$ & $24.6(22.5-26.2)$ & $23.5(21.8-26.1)$ & 0.026 \\
\hline SBP (mmHg) & $130(120-144)$ & $130(120-146)$ & $130(120-142)$ & 0.579 \\
\hline $\mathrm{DBP}(\mathrm{mmHg})$ & $79(70-86)$ & $80(72-87)$ & $75(70-83)$ & $<0.001$ \\
\hline ApoA $(g / L)$ & $1.1(1.0-1.3)$ & $1.1(1.0-1.2)$ & $1.2(1.1-1.4)$ & $<0.001$ \\
\hline ApoB $(g / L)$ & $0.8(0.6-0.9)$ & $0.8(0.6-0.9)$ & $0.8(0.6-0.9)$ & 0.714 \\
\hline ApoE (mg/L) & $32(25-41)$ & $30(24-39)$ & $34(28-43)$ & 0.004 \\
\hline Total-C (mmol/L) & $4.0(3.3-4.6)$ & $3.8(3.2-4.5)$ & $4.1(3.5-4.8)$ & 0.005 \\
\hline HDL-C (mmol/L) & $0.9(0.8-1.2)$ & $0.9(0.8-1.1)$ & $1.0(0.9-1.2)$ & $<0.001$ \\
\hline LDL-C (mmol/L) & $2.3(1.8-2.8)$ & $2.3(1.7-2.8)$ & $2.4(1.9-3.0)$ & 0.071 \\
\hline Lipoprotein(a) (mg/L) & $107(55-207)$ & $107(52-209)$ & $109(60-203)$ & 0.800 \\
\hline Triglycerides $(\mathrm{mmol} / \mathrm{L})$ & $1.4(1.0-2.1)$ & $1.4(0.9-2.2)$ & $1.3(1.0-2.1)$ & 0.645 \\
\hline ApoA/ApoB & $1.4(1.2-1.8)$ & $1.4(1.2-1.7)$ & $1.5(1.3-2.0)$ & 0.009 \\
\hline HDL-C/LDL-C & $0.4(0.3-0.5)$ & $0.4(0.3-0.5)$ & $0.4(0.3-0.6)$ & 0.204 \\
\hline PTH (pg/ml) & $41(32-54)$ & $42(32-55)$ & $41(31-54)$ & 0.275 \\
\hline $25(\mathrm{OH}) \mathrm{D}(\mathrm{ng} / \mathrm{ml})$ & $13.2(9.2-19.0)$ & $13.9(9.7-19.3)$ & $12.2(8.5-17.9)$ & 0.093 \\
\hline Calcium $(\mathrm{mmol} / \mathrm{L})$ & $2.2(2.1-2.3)$ & $2.2(2.1-2.3)$ & $2.2(2.1-2.3)$ & 0.890 \\
\hline Phosphorus (mmol/L) & $1.1(1.0-1.2)$ & $1.1(1.0-1.2)$ & $1.2(1.0-1.3)$ & 0.001 \\
\hline GA-L $(\%)^{\mathrm{a}}$ & $20.9(17.4-26.1)$ & $20.9(17.3-26.2)$ & $20.9(17.4-26.1)$ & 0.959 \\
\hline $\mathrm{HbAlc}(\%)$ & $8.1(6.7-9.7)$ & $8.2(6.8-9.9)$ & $8.0(6.6-9.6)$ & 0.244 \\
\hline $\mathrm{RBG}(\mathrm{mmol} / \mathrm{L})$ & $7.1(5.7-10.1)$ & $7.1(5.8-10.2)$ & $6.8(5.4-9.9)$ & 0.406 \\
\hline
\end{tabular}

Data are presented as median (IQR) values. BMI, body mass index; SBP, systolic blood pressure; DBP, diastolic blood pressure; ApoA, apolipoprotein A; ApoB, apolipoprotein B; ApoE, apolipoprotein E; Total-C, total cholesterol; HDL-C, high-density lipoprotein cholesterol; LDL-C, low-density lipoprotein cholesterol; PTH, parathyroid hormone; 25(OH)D, 25-hydroxyvitamin D; GA-L, glycated albumin; HbA1c, glycosylated hemoglobin; RBG, random blood glucose. ${ }^{\mathrm{a}} n=449$.

TABLE 2: Association among sex 25(OH)D groups, and blood glucose and lipid profiles $(n=507)$.

\begin{tabular}{|c|c|c|c|c|c|c|c|}
\hline & \multicolumn{2}{|c|}{ Male } & \multicolumn{2}{|c|}{ Female } & \multirow{2}{*}{$\begin{array}{c}\text { Sex } \\
P \\
\end{array}$} & \multirow{2}{*}{$\begin{array}{c}25(\mathrm{OH}) \mathrm{D} \\
P\end{array}$} & \multirow{2}{*}{$\begin{array}{c}\text { Interaction } \\
P\end{array}$} \\
\hline & Low $25(\mathrm{OH}) \mathrm{D}$ & High 25(OH)D & Low $25(\mathrm{OH}) \mathrm{D}$ & High $25(\mathrm{OH}) \mathrm{D}$ & & & \\
\hline $\mathrm{N}$ & 145 & 174 & 104 & 81 & & & \\
\hline ApoA (g/L) & $1.05 \pm 0.22$ & $1.11 \pm 0.19$ & $1.22 \pm 0.26$ & $1.22 \pm 0.21$ & $<0.001$ & 0.098 & 0.105 \\
\hline ApoB (g/L) & $0.79 \pm 0.23$ & $0.77 \pm 0.20$ & $0.80 \pm 0.24$ & $0.78 \pm 0.23$ & 0.070 & 0.534 & 0.964 \\
\hline $\operatorname{ApoE}(\mathrm{mg} / \mathrm{L})$ & $34.7 \pm 16.5$ & $33.8 \pm 19.3$ & $39.9 \pm 18.0$ & $34.3 \pm 13.6$ & 0.001 & 0.033 & 0.171 \\
\hline Lipoprotein(a) (mg/L) & $195.3 \pm 204.8$ & $141.3 \pm 137.9^{* \dagger}$ & $164.2 \pm 202.9$ & $202.4 \pm 222.4$ & 0.559 & 0.880 & 0.010 \\
\hline Total-C $(\mathrm{mmol} / \mathrm{L})$ & $4.00 \pm 1.15$ & $3.97 \pm 1.12$ & $4.30 \pm 1.24$ & $4.17 \pm 0.96$ & $<0.001$ & 0.665 & 0.690 \\
\hline $\mathrm{HDL}-\mathrm{C}(\mathrm{mmol} / \mathrm{L})$ & $0.92 \pm 0.26$ & $0.98 \pm 0.54$ & $1.08 \pm 0.40$ & $1.10 \pm 0.28$ & $<0.001$ & 0.083 & 0.441 \\
\hline LDL-C (mmol/L) & $2.43 \pm 1.07$ & $2.28 \pm 0.74$ & $2.51 \pm 1.00$ & $2.46 \pm 0.85$ & 0.004 & 0.544 & 0.688 \\
\hline Triglycerides (mmol/L) & $1.8 \pm 1.4$ & $2.8 \pm 7.9$ & $1.9 \pm 1.6$ & $2.4 \pm 7.0$ & 0.359 & 0.152 & 0.742 \\
\hline АроA/AроB & $1.45 \pm 0.61$ & $1.53 \pm 0.46$ & $1.74 \pm 1.41$ & $1.71 \pm 0.69$ & 0.032 & 0.592 & 0.339 \\
\hline HDL-C/LDL-C & $0.43 \pm 0.23$ & $0.47 \pm 0.30$ & $0.48 \pm 0.24$ & $0.50 \pm 0.22$ & 0.625 & 0.241 & 0.477 \\
\hline GA-L $(\%)^{\mathrm{a}}$ & $22.5 \pm 8.6$ & $23.4 \pm 8.7$ & $23.3 \pm 7.3$ & $22.2 \pm 8.8^{* \dagger}$ & 0.102 & 0.092 & 0.023 \\
\hline HbAlc (\%) & $8.5 \pm 2.2$ & $8.5 \pm 2.2$ & $8.5 \pm 2.0$ & $8.00 \pm 2.1$ & 0.136 & 0.009 & 0.091 \\
\hline $\mathrm{RBG}(\mathrm{mmol} / \mathrm{L})$ & $8.2 \pm 4.5$ & $8.9 \pm 4.8$ & $8.8 \pm 5.1$ & $7.6 \pm 3.5$ & 0.680 & 0.515 & 0.028 \\
\hline
\end{tabular}

Data are presented as mean \pm SD. ApoA, apolipoprotein A; ApoB, apolipoprotein B; ApoE, apolipoprotein E; Total-C, total cholesterol; HDL-C, high-density lipoprotein cholesterol; LDL-C, low-density lipoprotein cholesterol; 25(OH)D, 25-hydroxyvitamin D; GA-L, glycated albumin; HbA1c, glycosylated hemoglobin; RBG, random blood glucose. Data were analyzed using two-way analysis of covariance adjusted for age, BMI, season, marital status, smoking status, alcohol use behavior, insulin use, family history of diabetes, and diabetes duration. The levels of Apo B, Apo E, Total-C, HDL-C, LDL-C, lipoprotein(a), triglycerides, Apo A/Apo B, HDL-C/LDL-C, 25(OH)D, GA-L, HbAlc, and RBG were log-transformed for the analysis. ${ }^{a} n=449 .{ }^{*} P<0.05$ vs. female within the same $25(\mathrm{OH}) \mathrm{D}$ subjects. ${ }^{\dagger} P<0.05$ vs. low $25(\mathrm{OH}) \mathrm{D}$ within the same sex group. Boldface indicates significance $(P<0.05)$.

\section{Discussion}

The present study shows sex-specific correlations between 25(OH)D levels and the levels of three metabolic risk factors (lipoprotein(a), GA-L, and RBG) in T2DM patients. High serum $25(\mathrm{OH}) \mathrm{D}$ levels indicated a more favorable lipid profile in men and a more favorable glucose profile in women.

Vitamin D deficiency $(<20 \mathrm{ng} / \mathrm{mL}, 78.5 \%)$ was prevalent in the patients in our study, even in summer (79.6\%) and autumn (72.2\%), in which sun exposure is high [12]. The prevalence of vitamin $\mathrm{D}$ deficiency was much higher than 


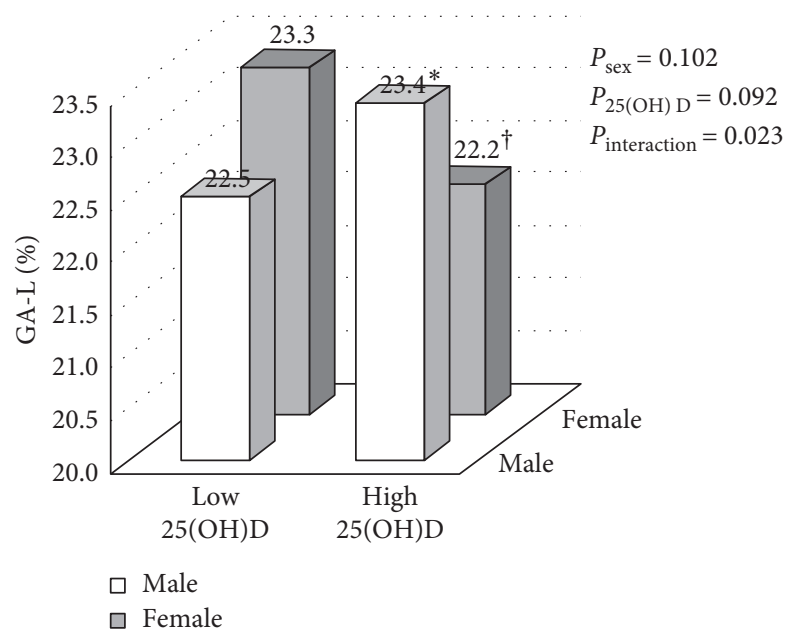

(a)

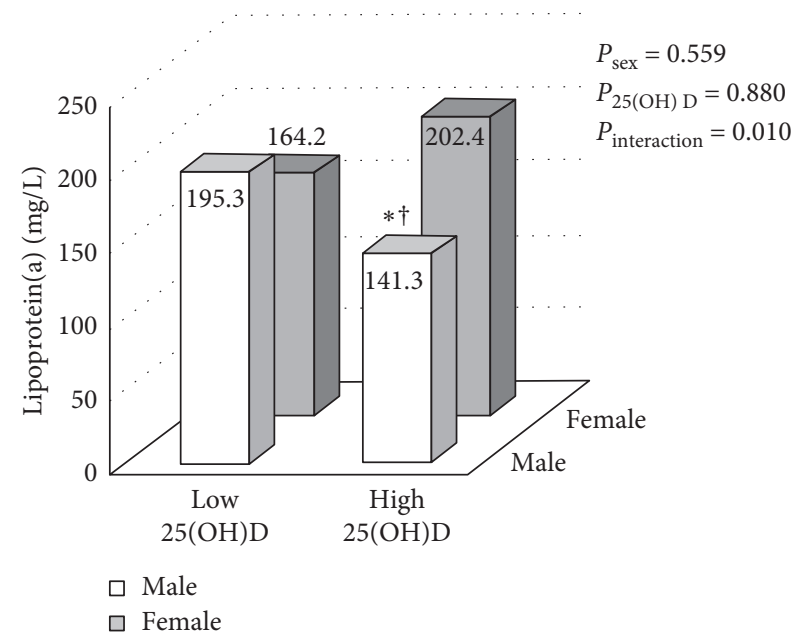

(b)

Figure 1: Joint association of 25(OH)D levels and sex on lipoprotein(a) and glycated albumin (GA-L). The values for lipoprotein (a) and GA-L were log-transformed for two-way analysis of covariance. The analysis was adjusted for age, body mass index, season, marital status, smoking status, alcohol use, insulin use, family history of diabetes, and diabetes duration. ${ }^{\#} \mathrm{GA}-\mathrm{L}, n=449 .{ }^{*} P<0.05$ vs. women in the same $25(\mathrm{OH}) \mathrm{D}$ group. ${ }^{\dagger} \mathrm{P}<0.05$ vs. low $25(\mathrm{OH}) \mathrm{D}$ in the same sex group.

TABLE 3: Multiple linear regression analysis with lipoprotein(a), GA-L, and RBC as dependent variables.

\begin{tabular}{|c|c|c|c|c|c|c|}
\hline \multirow{3}{*}{ Variables } & \multicolumn{6}{|c|}{$25(\mathrm{OH}) \mathrm{D}(\mathrm{ng} / \mathrm{ml})$} \\
\hline & \multicolumn{2}{|c|}{ Model 1} & \multicolumn{2}{|c|}{ Model 2} & \multicolumn{2}{|c|}{ Model 3} \\
\hline & $\beta$ & $P$ & $\beta$ & $P$ & $\beta$ & $P$ \\
\hline \multicolumn{7}{|l|}{ Male } \\
\hline Lipoprotein(a) (mg/L) & -0.203 & $<0.001$ & -0.188 & 0.002 & -0.185 & 0.002 \\
\hline GA-L (\%) & 0.101 & 0.088 & 0.029 & 0.638 & 0.054 & 0.372 \\
\hline RBG (mmol/L) & 0.07 & 0.211 & 0.058 & 0.331 & 0.054 & 0.366 \\
\hline \multicolumn{7}{|l|}{ Female } \\
\hline Lipoprotein(a) (mg/L) & 0.070 & 0.345 & 0.072 & 0.378 & 0.073 & 0.381 \\
\hline GA-L (\%) & -0.077 & 0.331 & -0.083 & 0.328 & -0.135 & 0.118 \\
\hline $\mathrm{RBG}(\mathrm{mmol} / \mathrm{L})$ & -0.150 & 0.041 & -0.189 & 0.016 & -0.176 & 0.028 \\
\hline
\end{tabular}

25(OH)D, 25-hydroxyvitamin D; GA-L, glycated albumin; RBG, random blood glucose. The levels of lipoprotein(a), 25(OH)D, GA-L, and RBG were logtransformed for the analysis. $\beta$, standardized coefficient; linear regression model was used. Model 1 was unadjusted; Model 2 was adjusted for age, PTH, season, marital status, smoking status, alcohol use behavior, insulin use, family history of diabetes, and diabetes duration; Model 3 included terms for Model 2 and BMI. ${ }^{a} n=449$. Boldface indicates significance $(P<0.05)$.

that in a prior study of T2DM patients in Xiamen, China (52.6\%) [3]. This difference may partly reflect differences in sun exposure, which stimulates vitamin $\mathrm{D}$ production in the skin (Xiamen $24^{\circ} \mathrm{N}$ latitude vs. Xi' an $34^{\circ} \mathrm{N}$ latitude). These results suggest that $\mathrm{T} 2 \mathrm{DM}$ patients, especially those in higher latitudes, should exercise outside, consume fatty fish, and take adequate amounts of vitamin $\mathrm{D}$ even in summer and autumn [13-15].

Previous studies linked high serum 25(OH)D levels with a low risk of metabolic disease [5]. Scragg et al. [7] found that $25(\mathrm{OH}) \mathrm{D}$ levels inversely correlated with insulin resistance in non-Hispanic whites and Mexican Americans but not African-Americans, which suggests that the correlation is ethnicity-dependent. Studies assessing this relationship in the Chinese population are limited [3, 9, 16-19]. Two studies in China identified low serum $25(\mathrm{OH}) \mathrm{D}$ concentration as a risk factor for insulin resistance and metabolic syndrome in T2DM patients in analyses adjusted for confounding factors including BMI $[3,17]$. Conversely, another study in China found that $25(\mathrm{OH}) \mathrm{D}$ levels directly correlated with insulin resistance in men, but not women or both sex combined [10].

Lipoprotein(a) is an LDL-like protein and a potential risk factor for cardiovascular disease, especially in adults with impaired glucose metabolism [20, 21]. In the present study, serum 25(OH)D levels negatively correlated with lipoprotein(a) levels in men, and the association remained significant after adjusting for several confounding factors. GA-L is a better indicator of short-term glycemic control (about 2-3 weeks) than is HbAlc [22]; however, the percent reductions in $\mathrm{HbA} 1 \mathrm{c}$ and GA-L levels were similar after insulin treatment in the study by Takahashi et al. [23]. We found that women in the high $25(\mathrm{OH}) \mathrm{D}$ group had lower GA$\mathrm{L}$ levels than did those in the low $25(\mathrm{OH}) \mathrm{D}$ group. Serum $25(\mathrm{OH}) \mathrm{D}$ levels also correlated inversely with RBG levels in women, even after adjusting for BMI. Our results suggest that $25(\mathrm{OH}) \mathrm{D}$ preserves lipid and glucose metabolism in men and 
women with T2DM through different pathways, which may be linked to sex hormones.

The sex-specific association of $25(\mathrm{OH}) \mathrm{D}$ with metabolic risk factors may reflect differential effects of endogenous sex hormones and sex hormone-binding globulin (SHBG) on the risk factors [24]. Ding et al. [24] found that women with T2DM had higher testosterone levels, whereas men had lower levels of testosterone; SHBG levels inversely correlated with risk more strongly in women than in men. Furthermore, hyperandrogenic condition, such as polycystic ovarian syndrome in women, and hypoandrogenism in men have been strongly associated with cardiometabolic risk [24, 25]. Recent studies showed a significant sex-related relationship between the levels of 25(OH)D and several sex hormones, including SHBG, estradiol, and testosterone in adults [26, 27]. However, levels of neither sex hormones nor SHBG were determined in our study. Other sex-specific factors such as physical activity, smoking, fat distribution, and eating habits may also partly explain the sex-related contribution of $25(\mathrm{OH}) \mathrm{D}$ to T2DM development. Women subjects with overweight/obesity and higher frequency of smoking in men were observed to be significantly associated with higher incidence of metabolic syndrome and lower concentrations of $25(\mathrm{OH}) \mathrm{D}$ as well $[15,28,29]$. The associations of sex and $25(\mathrm{OH}) \mathrm{D}$ with metabolic risk factor were needed to be clarified in future studies.

The present study has several limitations. First, the amount of time the patients spent in the sun was not recorded. We did, however, use season as a proxy for sun exposure. Second, because this was a cross-sectional study, it is difficult to make causal inferences. Third, lifestyle factors such as physical activity and diet were not considered; this should be done in future studies. Finally, the sample size of this study was limited. Prospective studies with larger sample sizes are required to fully investigate the role of vitamin $\mathrm{D}$ in the development of T2DM. Despite the limitation, our study was the first to examine the relationships between serum $25(\mathrm{OH})$ $\mathrm{D}$ levels and metabolic risk factors on a sex-specific basis. It suggested that the protective effect of maintaining higher $25(\mathrm{OH}) \mathrm{D}$ levels against the development of T2DM may be through different mechanism in Chinese women and men.

\section{Conclusions}

Serum 25(OH)D levels negatively correlated with the levels of several metabolic risk factors in a sex-dependent manner in T2DM patients. Higher serum 25(OH)D levels indicated a more favorable lipid profile in men and a more favorable glucose profile in women. Sex-targeted intervention strategies of T2DM would be recommended.

\section{Data Availability}

The data used to support the findings of this study are available from the corresponding author upon request.

\section{Conflicts of Interest}

The authors have no conflicts of interest to declare.

\section{Authors' Contributions}

Xiaomin Sun and Sirui Zhou contributed equally to this work.

\section{Acknowledgments}

The authors acknowledge all the participants in this study. This study was supported by the National Natural Science Foundation of China (no. 81703220), the Fundamental Research Funds for the Central Universities (no.xjj2018148), and funds for scientific research projects ofXi'an Aerospace General Hospital (no.2019KY002).

\section{Supplementary Materials}

Comparison of the vitamin D status according to sex groups. (Supplementary Materials)

\section{References}

[1] G. Roglic, "WHO global report on diabetes: a summary," International Journal of Noncommunicable Diseases, vol. 1, no. 1 , pp. 3-8, 2016.

[2] L. Wang, P. Gao, M. Zhang et al., "Prevalence and ethnic pattern of diabetes and prediabetes in China in 2013," Journal of the American Medical Association, vol. 317, no. 24, pp. 2515-2523, 2017.

[3] J. Zhang, J. Ye, G. Guo et al., "Vitamin D status is negatively correlated with insulin resistance in Chinese type 2 diabetes," International Journal of Endocrinology, vol. 2016, Article ID 1794894, 7 pages, 2016.

[4] M. Clemente-Postigo, A. Muñoz Garach, M. Serrano et al., "Serum 25-hydroxyvitamin D and adipose tissue vitamin D receptor gene expression: relationship with obesity and type 2 diabetes," Journal of Clinical Endocrinology \& Metabolism, vol. 100, no. 4, pp. E591-E595, 2015.

[5] M. Eliades and A. G. Pittas, "Vitamin D and type 2 diabetes," Clinical Reviews in Bone and Mineral Metabolism, vol. 7, no. 2, pp. 185-198, 2009.

[6] H. Khan, S. Kunutsor, O. H. Franco, and R. Chowdhury, "Vitamin D, type 2 diabetes and other metabolic outcomes: a systematic review and meta-analysis of prospective studies," Proceedings of the Nutrition Society, vol. 72, no. 1, pp. 89-97, 2013.

[7] R. Scragg, M. Sowers, and C. Bell, "Serum 25-hydroxyvitamin $\mathrm{D}$, diabetes, and ethnicity in the third national health and nutrition examination survey," Diabetes Care, vol. 27, no. 12, pp. 2813-2818, 2004.

[8] Y. Lu, Y. J. Zheng, N. J. Wang et al., “The relationship between vitamin $\mathrm{D}$ and type 2 diabetes is intriguing: glimpses from the spect-China study," Annals of Nutrition and Metabolism, vol. 71, no. 3-4, pp. 195-202, 2017.

[9] Y. Wang, S. Si, J. Liu et al., "The associations of serum lipids with vitamin D status," Plos One, vol. 11, no. 10, Article ID e0165157, 2016.

[10] W. Wang, S. Ye, L. Qian, and X. Xing, "Sex-specific association of serum 25-hydroxyvitamin D," Journal of Nutritional Science and Vitaminology, vol. 64, no. 3, pp. 173-178, 2018.

[11] American Diabetes Association, "Diagnosis and classification of diabetes mellitus," Diabetes Care, vol. 34, no. Supplement_ 1, pp. S62-S69, 2011. 
[12] M. F. Holick, "Vitamin D: importance in the prevention of cancers, type 1 diabetes, heart disease, and osteoporosis," The American Journal of Clinical Nutrition, vol. 79, no. 3, pp. 362-371, 2004.

[13] H. C. J. P. Janssen, M. H. Emmelot-Vonk, H. J. J. Verhaar, and Y. T. Van Der Schouw, "Determinants of vitamin D status in healthy men and women aged 40-80 years," Maturitas, vol. 74, no. 1, pp. 79-83, 2013.

[14] P. Lips, N. M. Van Schoor, and R. T. De Jongh, "Diet, sun, and lifestyle as determinants of vitamin D status," Annals of the New York Academy of Sciences, vol. 1317, no. 1, pp. 92-98, 2014.

[15] R. Tonnesen, P. H. Hovind, L. T. Jensen, and P. Schwarz, "Determinants of vitamin D status in young adults: influence of lifestyle, sociodemographic and anthropometric factors," BMC Public Health, vol. 16, no. 1, 2016.

[16] X. Yin, Q. Sun, X. P. Zhang et al., "Serum 25(OH) D is inversely associated with metabolic syndrome risk profile among urban middle-aged Chinese population," Nutrition Journal, vol. 11, no. 1, 2012.

[17] G. T. Pan, J. F. Guo, S. L. Mei et al., "Vitamin D deficiency in relation to the risk of metabolic syndrome in middle-aged and elderly patients with type 2 diabetes mellitus," Journal of Nutritional Science and Vitaminology, vol. 62, no. 4, pp. 213-219, 2016.

[18] J. Fu, L. Han, Y. Zhao et al., "Vitamin D levels are associated with metabolic syndrome in adolescents and young adults: the BCAMS study," Clinical Nutrition, vol. 38, no. 5, pp. 2161-2167, 2019.

[19] W. Chen, Y. Sha, Y. Chen, Y. Shi, D. Yin, and H. Wang, "Vitamin D, parathyroid hormone, and serum lipid profiles in a middle-aged and elderly Chinese population," Endocrine Practice, vol. 20, no. 6, pp. 556-565, 2014.

[20] A. N. Qasim, S. S. Martin, N. N. Mehta et al., "Lipoprotein (a) is strongly associated with coronary artery calcification in type-2 diabetic women," International Journal of Cardiology, vol. 150, no. 1, pp. 17-21, 2011.

[21] Y. B. Jiang, K. Guo, M. Chen, J. Bao, C. Shen, and Y. Li, "Serum lipoprotein (a) positively correlates with coronary artery calcification in low-risk Chinese han patients: a study from a single center," Plos One, vol. 8, no. 8, 2013.

[22] Y. Tahara and K. Shima, "Kinetics of hba (1c), glycated albumin, and fructosamine and analysis of their weight-functions against preceding plasma-glucose level," Diabetes Care, vol. 18, no. 4, pp. 440-447, 1995.

[23] S. Takahashi, H. Uchino, T. Shimizu et al., "Comparison of glycated albumin (Ga) and glycated hemoglobin (Hbalc) in type 2 diabetic patients: usefulness of Ga for evaluation of short-term changes in glycemic control," Endocrine Journal, vol. 54, no. 1, pp. 139-144, 2007.

[24] E. L. Ding, Y. Song, V. S. Malik, and S. Liu, "Sex differences of endogenous sex hormones and risk of type 2 diabetes: a systematic review and meta-analysis," Journal of the American Medical Association, vol. 295, no. 11, pp. 1288-1299, 2006.

[25] D. K. Sanghera, B. R. Sapkota, C. E. Aston, and P. R. Blackett, "Vitamin D status, gender differences, and cardiometabolic health disparities," Annals of Nutrition and Metabolism, vol. 70, no. 2, pp. 79-87, 2017.

[26] G. M. Anic, D. Albanes, S. Rohrmann et al., "Association between serum 25-hydroxyvitamin D and serum sex steroid hormones among men in NHANES," Clinical Endocrinology, vol. 85, no. 2, pp. 258-266, 2016.

[27] D. Zhao, P. Ouyang, I. H. De Boer et al., "Serum vitamin D and sex hormones levels in men and women: the multi-ethnic study of atherosclerosis (mesa)," Maturitas, vol. 96, pp. 95102, 2017.

[28] E. N. Kassi, S. Stavropoulos, P. Kokkoris et al., "Smoking is a significant determinant of low serum vitamin D in young and middle-aged healthy males," Hormones, vol. 14, no. 2, pp. 245-250, 2015.

[29] B. Xi, D. He, Y. Hu, and D. Zhou, "Prevalence of metabolic syndrome and its influencing factors among the Chinese adults: the China health and nutrition survey in 2009," Preventive Medicine, vol. 57, no. 6, pp. 867-871, 2013. 